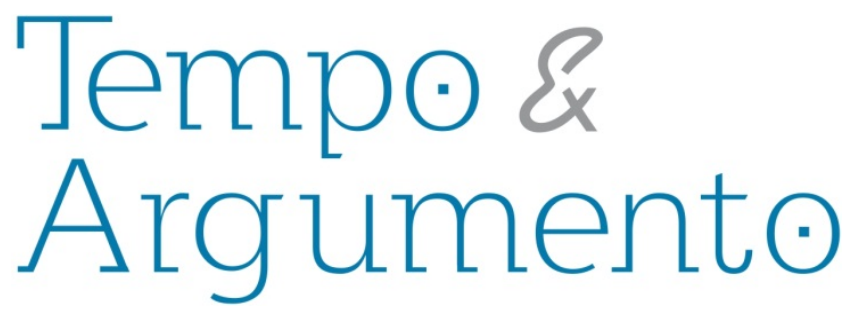

\title{
Infancia y diáspora: dos escritoras cubanas cuentan sus vidas
}

\begin{abstract}
Resumen
Con el enfoque en las representaciones literarias de la infancia, este artículo reflexiona sobre la memoria colectiva cubana en su dimensión transnacional y diaspórica. A partir del año 1959, la sociedad cubana está marcada por numerosas oleadas migratorias al curso de la revolución cubana y la formación de un estado socialista. Desde que el régimen castrista se dirigió hacia una ideología rígida, muchos cubanos han vivido una desilusión con las esperanzas revolucionarias. La reflexión sobre una isla en el proceso de volverse un espacio recluido en vez de liberado es un tema recurrente en la literatura cubana contemporánea. En el marco de una lectura comparativa, se analiza Todos se van (2006), de Wendy Guerra, y El mañana: memorias de un éxodo cubano (2006), escrita por la periodista Mirta Ojito, que vive en los Estados Unidos. Estas novelas autobiográficas muestran como se entrelazan la reconstrucción narrativa de la infancia con el momento histórico de una diasporización creciente de la sociedad cubana en los años 70. Las escritoras cubanas no sólo reconstruyen el mundo perdido de su infancia, sino también tratan de recuperar la(s) historia(s) de una nación diseminada en el mundo.
\end{abstract}

Palabras clave: Infancia; Literatura Cubana; Diáspora; Memoria Colectiva.

\section{Andrea Gremels}

Estudió lenguas y literaturas románicas (español, francés, portugués), sociología y americanística en la Johann Wolfgang Goethe-Universität Fráncfort del Meno (Alemania). Es colaboradora científica y docente en la cátedra de literaturas latinoamericanas y francófonas. En el marco de su tesis de doctorado investigó la literatura cubana contemporánea entre exilio y transculturalidad. Alemania

a.gremels@em.uni-frankfurt.de

\section{Para citar este artículo:}

GREMELS, Andrea. Infancia y diáspora: dos escritoras cubanas cuentan sus vidas. Revista Tempo e Argumento, Florianópolis, v. 7, n. 14, p. 116 - 131, jan./abr. 2015.

\author{
DOI: $10.5965 / 2175180307142015116$
}

http://dx.doi.org/10.5965/2175180307142015116 


\section{Children and Diaspora: Two Cuban writers narrate their lives}

\begin{abstract}
Focusing on literary representations of childhood, this article reflects on the Cuban collective memory in its transnational and diasporic dimension. Since 1959, Cuban society is marked by numerous migratory waves in the course of the Cuban Revolution and the formation of a socialist State. Since the Castro regime leaded to a rigid ideology, many Cubans have lived a disappointment with revolutionary hopes. The reflection on an island in the process of becoming a confined space instead of a freed one is a recurring theme in contemporary Cuban literature. As part of a comparative reading, we have analyzed Todos se van (2006), by Wendy Guerra, and El mañana: memorias de un éxodo cubano (2006), written by journalist Mirta Ojito, who lives in the United States. These autobiographical novels show how the narrative reconstruction of childhood are interwoven with the historical moment of a growing diasporisation of Cuban society in the 70's. The Cuban writers not only reconstruct the lost world of their childhood, but also try to recover the(s) history(ies) of a nation spread in the world.
\end{abstract}

Keywords: Childhood; Cuban Literature; Diaspora; Collective memory.

\section{Infância e diáspora: Duas escritoras cubanas contam suas vidas}

\section{Resumo}

Com foco nas representações literárias da infância, este artigo reflete sobre a memória coletiva cubana em sua dimensão transnacional e de diáspora. A partir do ano de 1959, a sociedade cubana é marcada por numerosas ondas migratórias no curso da revolução cubana e da formação de um estado socialista. Desde que o regime castrista se encaminhou para uma ideologia rígida, muitos cubanos viveram uma desilusão com as esperanças revolucionárias. A reflexão sobre uma ilha no processo de tornar-se um espaço recluso em vez de liberado é um tema recorrente da literatura cubana contemporânea. Com base em uma leitura comparativa, analisam-se Todos se vão (2006), de Wendy Guerra, e El mañana: memorias de um éxodo cubano (2006), escrita pela jornalista Mirta Ojito, que vive nos Estados Unidos. Estas novelas autobiográficas mostram como se entrelaça a reconstrução narrativa da infância com o momento histórico de uma diasporização crescente da sociedade cubana dos anos 1970. As escritoras cubanas não somente reconstroem o mundo perdido de sua infância, mas também tratam de recuperar a(s) história(s) de uma nação disseminada no mundo.

Palavras-chave: Infância; Literatura cubana; Diáspora; Memória coletiva 
Hoy día, Cuba es uno de los países con el porcentaje más alto de emigrantes, si se cuenta que entre el $15 \%$ y el $20 \%$ de su población total vive fuera de la isla (cf. NUEZ, 1998, p. 28). En este siglo XXI, cuando ya se ha celebrado el 55 aniversario del triunfo de la Revolución cubana, la diáspora aún crece continuamente. Algunas de las numerosas oleadas migratorias que han tenido lugar desde que el régimen castrista asumió una ideología rígida, han tenido las características de éxodo escandaloso, si pensamos por ejemplo en el así llamado éxodo de Mariel, de 1980. Ese año, miles de cubanos ocuparon la embajada de Perú para pedir asilo y presionar al régimen la autorización de salir de Cuba. Cuando Castro cede a esta presión, 125000 cubanos -que más tarde serían Ilamados marielitos- salen en barcos desde el puerto del Mariel rumbo a Miami. La fuga a través del mar ha sido un leitmotiv de la historia cubana contemporánea. No solo a través de botes sofisticados, manejados por traficantes, sino por medio de rústicas embarcaciones llamadas balsas. En los años 90, el colapso del bloque socialista de Europa del Este causó en la isla una crisis económica y social tan aguda (el llamado "período especial”), que provocó un aumento masivo de salidas y, en agosto de 1994, la famosa crisis de los Balseros. Unos 35000 cubanos arriesgaron sus vidas en el intento de llegar a las costas de los Estados Unidos en esas balsas improvisadas. ${ }^{1}$

Tales momentos históricos de emigraciones masivas se han grabado en la memoria colectiva de los cubanos, una memoria que no sólo se forma dentro de la isla. La tenemos que considerar también en una dimensión transnacional y diaspórica. En este contexto, la literatura desempeña un papel esencial como medio que (re)construye y recupera la memoria cultural dentro y más allá de las fronteras nacionales (cf. ERLL, 2011). Enfocaré, aquí, dos obras de corte autobiográfico de escritoras cubanas contemporáneas: Todos se van, de Wendy Guerra, autora que escribe en La Habana pero publica en España, ${ }^{2}$

\footnotetext{
${ }^{1}$ Tras el Maleconazo, un estallido de violencia en La Habana en protesta por la extrema situación en que se vivía, el gobierno decide abrir las fronteras y dejar que todo el que deseara emigrar a través del mar lo hiciera. Durante semanas miles de cubanos se lanzaron a las aguas del golfo de México que separa Cuba de los Estados Unidos. Lo hacían en botes, frágiles embarcaciones, balsas y todo lo que pudiera servir para navegar (aún hoy los balseros siguen ocupando espacio en los titulares de noticias dedicados a Cuba). Pero el primer gran éxodo marítimo tuvo lugar en 1965 a través de Boca de Camarioca, un pequeño pesquero ubicado al este de la ciudad de Matanzas. Por allí salieron personas de la clase media alta y baja que temieron o simplemente no comulgaron con el socialismo que se estaba implementando.

${ }^{2}$ Es de destacar que Todos se van no se distribuye en Cuba, sino que circula de mano en mano en forma de fotocopia. Cf. Briand (2009).
} 

marcados por una creciente división social entre los que se van y los que se quedan. Esta división no solo se debe a conflictos económicos sino también a los ideológicos, ${ }^{3}$ que culminan en el éxodo de Mariel. A continuación, analizaré cómo ambas autoras reflejan lo que quiero llamar la diasporización creciente de la sociedad cubana a través de sus memorias de infancia. En este contexto, me interesa reflexionar sobre la formación de una memoria colectiva que -tanto dentro como fuera de la isla- se constituye a la vez como memoria diaspórica, caracterizada por el afán de reconstruir la historia cubana en la búsqueda de una identidad personal y colectiva. ${ }^{4}$ Esta búsqueda concierne también a la configuración de una "comunidad imaginada" en el sentido que le da Benedict Anderson (1983).

No es de extrañar que la memoria diaspórica de la literatura cubana se entrelace, en muchos casos, con la reconstrucción narrativa de la infancia, al ser esta última, la infancia, el lugar, el tiempo y el símbolo de un origen perdido. "He pagado un precio muy alto por crecer sola mientras todos se marchaban de la isla. Me fueron abandonando poco a poco [...]; estoy fuera del mundo" (GUERRA, 2006, p. 9), dice la protagonista de Todos se van. Este "estar fuera del mundo" revela que la representación literaria de la infancia no sirve para constituirla como un estado idílico y carente de conflictos, sino más bien para destacar que las fracturas, separaciones y desilusiones forman parte integral de la infancia, especialmente cuando ella está afectada por el poder autoritario de un régimen como el de Cuba. ${ }^{5}$

\footnotetext{
${ }^{3}$ Es a partir de 1971 -tal vez a partir de la gran Ofensiva Revolucionara, en 1968- que el gobierno asume una sola, monolítica ideología que entonces convierte a la Revolución en un régimen que restringe y que se vuelve rígido.

${ }^{4}$ En relación con la memoria colectiva como "almacén de conocimientos", del cual un grupo deriva una conciencia de unidad, véase Assmann y Czaplicka (1995, p. 130). Con respecto a la conservación de los recuerdos por la que la diáspora se constituye como grupo que crea un sentido común, véase Safran (1991, pp. 83 y s.) y Mayer (2005, p. 13).

5 "Es una reflexión acerca de cómo el poder afecta a la infancia y la juventud“, dice el director colombiano Sergio Cabrera refiriéndose a la novela de Wendy Guerra En el año 2013 empezó a adaptarla para el cine. Ver: CORRESPONDAL-NOTICINE.COM: ‘http://www.noticine.com/iberoamerica/36-iberoamerica/19751sergio-cabrera-vuelve-a-la-gran-pantalla-con-qtodos-se-vanq.html). Acceso el: 28 mar. 2015. La película se
} 
Los análisis siguientes se basan en tres preguntas: ¿cómo se inscriben estos conflictos vividos en las dos novelas autobiográficas?, ¿qué papel desempeña la perspectiva de la niñez con respecto a la formación de una memoria colectiva en su dimensión transnacional? y ¿de qué manera las escritoras intentan recuperar la(s) historia(s) de una nación diseminada en el mundo a través del género autobiográfico, sea testimonial o ficcionalizado?

\section{Toda(s) la(s) historia(s) en el diario}

En la autobiografía ficcional de Wendy Guerra la infancia está representada por medio del diario. Esta forma de narración íntima crea una cercanía con el lector, reforzada por la autenticidad que la perspectiva infantil puede aportar. Esto se realiza estilísticamente a través de un lenguaje sencillo, frases cortas y el uso del presente: "un lenguaje desnudo y efectivo" desde "la mirada de una niña inusualmente lúcida y sensible", como propone Lilian Fernández-Hall (2007, s.p.). El diario es el alter ego y el interlocutor de la protagonista Nieve Guerra, quien a su vez puede ser considerada el alter ego de la autora, que re-leyó sus diarios de infancia y juventud escritos entre 1978 y 1990 para convertirlos en una novela autoficcional. ${ }^{6}$ Por lo tanto, en este proceso de reescritura la infancia narrada se ubica en el intersticio que queda entre la realidad y la ficción. Charlotte Michel considera esta autoficción como una novela de iniciación que retrasa la evolución de la protagonista en forma de "una quête identitaria". No obstante, destaca también que "esa búsqueda no va del no saber al saber, de la inocencia a la madurez, sino que desemboca en una desubicación total del personaje" (MICHEL, 2011, s.p.). Esta desubicación se debe al "mundo disperso" (GUERRA, 2006, p. 9) de la

estrenó por primera vez en diciembre de 2014, en el Festival de Cine de La Habana. Ver COLPRENSA: 〈http://www.elcolombiano.com/todos-se-van-el-regreso-cinematografico-de-sergio-cabrera-DX1415775». Acceso el: 28 mar. 2015.

${ }^{6}$ Con respecto a la autoficción como combinación de autobiografía y novela, véase Zipfel (2009). La autoficción subvierte las características del "pacto autobiográfico" planteado por Philippe Lejeune (1975). Este pacto se define por la identidad del autor y del narrador, tanto como del narrador y de la figura, la que le da credibilidad a la narración autobiográfica en cuanto a su referencialidad extratextual (ZIPFEL, 2009, p. 287-288). 

rupturas que impregnan su infancia con la experiencia de la soledad. ${ }^{7}$ Nieve, cuyo nombre contrasta con la condición tropical de la isla de Cuba, crece en un lugar idílico en Cienfuegos, una ciudad costera ubicada en el centro de la isla, y junto a su madre, una artista que trabaja para la radio local y es divorciada. La madre se casó de nuevo con un hombre sueco llamado Fausto, con quien Nieve mantenía una relación de gran confianza. Cuando la madre tiene que servir en la guerra de Angola durante unos meses -una medida de castigo por parte del régimen- el padre de Nieve, también artista, reclama la guardia de su hija en un juicio que gana. La mudanza resulta dramática para la niña, porque en el nuevo "hogar" sufre la violencia de su padre, que es alcohólico y la maltrata diariamente con golpes. Con él vive hasta que, años más tarde, la llevan a un Centro de Reeducación de Menores, que sirve además de internado de huérfanos. Cuando una mujer se interesa en adoptar a Nieve, su madre finalmente retoma la custodia por su hija. El diario de infancia cierra con la partida del padre para Miami, mientras que madre e hija van a vivir para La Habana. ${ }^{8}$

El tema principal que caracteriza la infancia de Nieve es el miedo: la angustia de estar sin protección ante el violento y arbitrario poder del padre, el desasosiego frente a la inseguridad cotidiana que origina una reclusión solitaria y el temor a las continuas separaciones de sus seres queridos. Esta experiencia de miedo aumenta porque ella, desde su perspectiva de niña, no entiende las circunstancias políticas que se le imponen a la vida de la familia. Paradójicamente, la ausencia de una conciencia política en el universo infantil va acompañada de la omnipresencia de la situación política en su mundo cotidiano. Un día, la madre le dice: "En Cuba la política está en lo que comes, en dónde

\footnotetext{
${ }^{7}$ Según Maurice Halbwachs, la primera experiencia del abandono y de la soledad hace que un niño entre en el mundo de los adultos, porque sus recuerdos de esta experiencia ya no son solamente el "souvenir d'enfant" (memoria del niño), sino al mismo tiempo un "souvenir d'adulte" - memoria del adulto (HALBWACHS, 1950, p. 21), de modo que estos recuerdos se incorporan en el cadre (el marco) de la memoria colectiva (ibíd., p. 21-23).

${ }^{8}$ La segunda mitad de la novela abarca la juventud de la protagonista. En el análisis, me enfocaré en el diario de la infancia.
} 
El protagonismo de la niña consiste en que no juzga ni se queja de las circunstancias en las que vive, sino que trata simplemente de sobrevivir en ellas (cf. FERNÁNDEZ-HALL, 2007, s.p.). Además, no hay alternativa porque no conoce otro mundo.

En este contexto, destaca el tema de la escasez de comida, algo que forma parte de la memoria colectiva cubana a partir de los años 60. El tema del hambre se ha vuelto un tópico de la literatura cubana contemporánea. ${ }^{9}$ Aparece también en Todos se van, de modo que el lector lo puede vincular con la situación económica en la isla. No obstante, la protagonista no sufre hambre por la falta de alimentos sino realmente por la privación de ellos a la que el padre la tortura. Entre el miedo a la conducta de desatención y a la violencia paterna, los sentimientos de culpa y el deseo de adaptarse a la situación para que mejore, Nieve, finalmente, toma una postura de autocastigo, o más bien de resistencia contra el poder paterno, y entra en una huelga de hambre: "Ahora soy yo la que no voy a comer más. Se acabó” (GUERRA, 2006, p. 60). No obstante, a pesar de que enflaquece radicalmente, esta resistencia no origina ningún cambio: "Sigo teniendo problemas con mi padre y la comida. Nunca me trae nada y cuando me trae me obliga a comer aunque sean las tres o las cuatro de la mañana. Me pega, pero no tanto para amoratarme" (ibíd., p. 78). Nieve no tiene forma de salir del círculo vicioso de los maltratos: "Sabía que me pegaría, lo sabía bien. Pero no puedo hacer nada” (ibíd., p. 54). El desamparo y la indefensión en que se encuentra la niña convierten la casa en una prisión, un espacio de encerramiento y un lugar amenazante: "Cuando entro a la casa estoy más en peligro que cuando estoy fuera. Dice mi madre que la puerta de la casa es lo más sagrado que hay pero ésta no es mi casa" (ibíd., p. 66).

Con la ayuda de una profesora que denuncia al padre ante las autoridades oficiales, Nieve consigue finalmente escapar de la casa-prisión. Sin embargo, los sentimientos de desamparo, soledad y orfandad se refuerzan cuando se muda al

\footnotetext{
${ }^{9}$ Esto cuenta especialmente para los autores del "Cuban boom" de los años 90, que reflejan la escasez de alimentos durante el período especial. El tema de la Cuba hambrienta y en decadencia lleva a una divulgación creciente de la literatura cubana en el mercado internacional del libro (cf. WHITFIELD, 2008).
} 

abandonan:

\begin{abstract}
Cada vez que cierro una puerta me parece que no voy a ver más a esas personas que están donde yo estaba. Las miro fijo, para que no se me olviden nunca. Es un momento pequeño, es un instante en que me llevo todo lo que hay allí con los ojos. Le puse a ese momento 'Los Nuncajamases' porque sé que nunca jamás volveré aquí y allá y a tantos lugares en los que he vivido (ibíd., p. 103).
\end{abstract}

En esta cita, el deseo de poder grabar todos los así llamados momentos “nuncajamases" revela una reflexión profunda sobre la memoria y su capacidad de guardar las imágenes de pérdida. Este modo reflexivo remite al mismo tiempo a la función de la escritura. El diario, como refugio, alter ego e interlocutor, es el único "hogar" para Nieve, el único lugar confiable y consistente en un mundo que se desintegra y fractura. Así, la escritura crea un espacio de resistencia que se observa, por ejemplo, en el momento en que la madre se marcha a Angola: "Estoy en huelga de Diario porque se Ilevaron a mi madre a la guerra de Angola. Esta página está en blanco en su honor" (ibíd., p. 19). La cita demuestra que la página vacía constituye un acto de lucha con y contra el silencio y el miedo a la pérdida. Al mismo tiempo, revela la dificultad de encontrar palabras para las despedidas, es decir, expresar lo indecible. Por lo tanto, Nieve intenta coleccionar y guardar los fragmentos de su desubicado mundo de la infancia, pero no consigue convertir esos fragmentos dispersos en una imagen que tenga sentido.

En cuanto a la diasporización de la sociedad cubana, la novela autoficcional expresa ante todo el efecto que tienen las partidas en el mundo frágil de la niñez y luego en la etapa de la juventud. La frustración y la inseguridad que sufre la protagonista, se deben además al hecho de que ella misma pierde la esperanza de irse como los demás (algo que se describe especialmente en el diario de la juventud). Queda sometida a los poderes masculinos: el del sistema que rige en Cuba y el de su padre, del que sigue dependiendo aún después de que él emigre para Miami, como lo muestra el hecho de que Nieve y su madre también piden la autorización de salida: 
Si mi padre se fue es que queremos irnos a Miami.

Si mi padre se fue y no nos vamos para Miami él tenía que darnos el permiso.

Ahora para darnos el permiso mi padre tiene que estar en Cuba.

Como mi padre no va a regresar a Cuba, no puedo irme de Cuba hasta que cumpla 18 años.

Mi madre [s]alió a la calle muy callada, [... ] no debería darse por vencida. (ibíd., p. 130 y s.)

En Todos se van el intento de irse aparece como una obsesión colectiva, la meta de una sociedad entera. Para todos los que no logran "escapar”, esto significa perseverar en la desesperación de quedar cautivo en un ambiente abandonado de una isla que parece volverse cada día más inhabitada e inhabitable. La novela está introducida por una cita de Charles Baudelaire: "La patria es la infancia”. Si -a través de esta referencia paratextualentendemos la infancia como símbolo de la patria, queda evidente que la infancia de Nieve representa a Cuba como un espacio fragmentado y desubicado. La despedida se ha inscrito en la memoria colectiva cubana como tema central. Así, se manifiesta al mismo tiempo que la memoria colectiva está dividida porque las historias cotidianas de familias separadas, niños abandonados y amigos perdidos diseñan una imagen sumamente contrastante de la versión historiográfica del régimen revolucionario, que oficialmente proclama la unidad y unanimidad del pueblo. La realidad cotidiana, descrita “desnudamente" en el diario, se opone drásticamente a cualquiera perspectiva romantizada de la infancia y asimismo a una perspectiva homogeneizadora de la historia cubana. La novela de Wendy Guerra crea entonces un espacio de "contra-memoria" (ERLL, 2005, p. 265) que se opone a la versión oficial y homogeneizadora de la memoria colectiva cubana. En este espacio literario resuenan las voces oficialmente silenciadas en esa voz infantil que trata de superar el silencio de las despedidas.

\section{Toda(s) la(s) historia(s) en el testimonio}

Mirta Ojito y su familia salieron de Cuba en 1980, por el puerto del Mariel, en un barco llamado El Mañana. Justamente es el nombre de este barco el que da título al libro de sus memorias personales, publicadas primero en inglés (Finding Mañana: A Memoir of a Cuban Exodus, Nueva York, 2005) y traducidas al español un año más tarde por el cubano 
Orlando Alomá (Random House/Vintage Español). Periodista de profesión (ganó el Pulitzer de reportajes nacionales en 2001), Ojito combina en sus memorias no solo testimonio autobiográfico y ficciones sino también documentos históricos. De esta manera crea una multiperspectiva, pues no sólo retrata su propia infancia en los años 70, sino que también da voz a distintos protagonistas del escenario político que determinaron el curso de los acontecimientos del Mariel. ${ }^{10}$ Según Ojito, el puente del Mariel, que conectó esa bahía al oeste de la ciudad de La Habana con Miami, alteró la historia de los dos países -Estados Unidos y Cuba- y "cambió el curso de miles de vidas" (OJITO, 2006, p. 12), incluyendo la suya. Constata que "estaba al tanto de las consecuencias y los rasgos generales del puente marítimo: las fechas, las estadísticas, el impacto -bueno y malo- y las imágenes televisadas de desesperación y esperanza, pero mi propia historia era una página en blanco" (ibíd., p. 11).

La motivación de escribir el libro nace entonces del deseo de llenar esa página en blanco, iniciada en su primera vuelta a Cuba en 1998, cuando fue "asaltada" por los recuerdos (ibíd., 9). Durante este viaje, que emprende dieciocho años después de su partida, surgen dos vehementes preguntas: ¿Por qué "yo y miles de cubanos nos enamoramos de la revolución”? y “¿cuándo fue que todo se volvió insoportable?” (ibíd., p. 10).

El testimonio de la infancia se acerca a las cuestiones de exclusión e inclusión que determinaron la vida de su familia en la década del 70 y en un ambiente marcado por una rígida ideología socialista. Esto se revela en el título del primer capítulo, "Gusanos”, un término despectivo con que los cubanos descalificaron a todos aquellos que consideraban "contrarrevolucionarios" solo porque querían emigrar. Precisamente, Mirta es hija de "gusanos", porque sus padres no ocultan ese deseo: "no recuerdo un momento en mi vida en que no supiera que la aspiración más acariciada de mis padres era algún día, de algún modo, irse de Cuba, como ya lo había hecho la mayor parte de la gente que

\footnotetext{
${ }^{10}$ Entre los protagonistas se encuentran Bernardo Benes, exiliado cubano en Miami que empezó a negociar con Castro para conseguir una apertura que permitiera las visitas de familiares exiliados a la isla; Héctor Sanyustiz, que demolió la cerca de la embajada de Perú, conduciendo un ómnibus público; Napoleón Vilaboa, que le propuso a Castro crear el puente del Mariel para permitir a exiliados cubanos buscar a sus familiares en barcos; y Mike Howell, el capitán estadounidense de La Mañana.
} 
conocíamos" (ibíd., p. 16). Sigue con una enumeración de amigos y familiares idos, dándose cuenta de que la despedida y la pérdida de personas queridas constituyen "sus memorias más tempranas" (ibíd.).

La conciencia de que la posición de sus padres crea conflictos con el sistema político empieza con su entrada a la escuela, en la que chocan los valores familiares y la ideología oficial cuando la maestra pregunta quién de los alumnos va a la iglesia. La niña, en su primera semana de clase, levanta la mano con entusiasmo, para luego entender que el gesto, de allí en adelante, la "marca” como "defectuosa” (ibíd., p. 24) y tendría la consecuencia de ser excluida del sistema revolucionario porque, como explica la maestra, no es Dios sino Fidel y la Revolución quienes le ponen la comida en la mesa y le dan los libros y lápices para venir a la escuela (ibíd., p. 24). Notablemente, a pesar de los obstáculos que enfrenta "como hija de gusanos confesos" (ibíd., p. 29), la formación escolar bajo el régimen castrista no deja de influir en Mirta, una buena alumna que participa en las actividades de la organización de Jóvenes Comunistas. No es solamente por el deseo de pertenecer sino también por creer en los ideales de la Revolución, "su designio mayor" (ibíd., p. 143), ${ }^{11}$ por lo que ella no toma una actitud de resistencia dentro del sistema escolar, que exige de los niños que "entreguen sus almas" (ibíd., p. 10). Por lo tanto, su testimonio no quiere culpabilizar ninguno de los dos "polos": la Revolución y la familia. A través de los recuerdos revisa más bien su conflicto: estar dividida entre las “dos lealtades diferentes" (ibíd., p. 152) que crean tensiones intergeneracionales dentro de la familia. Estas se intensifican durante los años de infancia: como "el deseo de salir se convirtió en un modo de vida" (ibíd., p. 17) dentro de la familia, que vive constantes frustraciones con la burocracia cubana en el intento de conseguir los papeles necesarios por emigrar, la protagonista anticipa sin cesar su propia despedida, luchando al mismo tiempo con la pregunta de si el deseo de sus padres realmente corresponde al suyo: "[I]ncluso después de decirle a mi padre que nos sacara de Cuba, no estaba segura de que yo lo seguiría" (ibíd., p. 87). Este conflicto culmina en 1980, cuando los padres finalmente ven que sus esperanzas pueden volverse realidad, pero temiendo a la vez que su hija se niegue a acompañarlos. Mirta Ojito documenta con vivacidad cómo "la oleada

\footnotetext{
${ }^{11}$ Habla también del "paraíso revolucionario" (OJITO, 2006, p. 73).
} 
Castro: “Que se vaya la escoria!” (ibíd., p. 195 y s.). La protagonista compara esta atmósfera hostil y violenta con una "guerra civil" (ibíd., p. 194), ${ }^{13}$ que abre brechas duras y desesperadas entre familiares, vecinos y amigos, un caos destructor que le imposibilita a la protagonista reconocer su propio país (cf. ibíd., p. 196).

Para la familia Ojito el Mariel resulta ser la "salvación”, la "liberación” anhelada de ese espacio de reclusión que es la isla (ibíd., p. 254). Además, en los Estados Unidos, como muchos otros cubanos, Mirta sigue su camino con éxito, especialmente con respecto a su carrera profesional de periodista. No obstante, el corte del "cordón umbilical” cubano (ibíd., p. 254), el desconsuelo por la separación definitiva de su tierra natal y la añoranza por su pasado perdido, la persiguen hasta llevarla a escribir El Mañana. El hecho de que Mirta Ojito no sólo revisita su propio pasado sino que indaga profundamente en el momento histórico del Mariel, mezclando documentación y ficción, historia personal e historia política, convierten a este libro en un aporte significativo para la memoria colectiva cubana. Al mismo tiempo, el libro ejemplifica cómo esta memoria se ha transnacionalizado y se despliega en el cruce de dos culturas (Travelling Memory, ERLL, 2011), la estadounidense y la cubana. Tanto la propia autora como muchos de los actores históricos que aparecen como figuras importantes en su reconstrucción historiográficonarrativa, viven diseminados por el mundo. Por ello, la narración de Ojito ofrece un diálogo entre las múltiples perspectivas conflictivas que existen en la isla y dentro de la diáspora. A pesar de su posición crítica frente al régimen castrista, la escritora emprende el trabajo de memoria para desarrollar su propia perspectiva múltiple frente a su pasado, lo que logra ante todo a través de la recuperación de la infancia. En su búsqueda de pertenencia como exiliada cubana en los Estados Unidos, Ojito destaca que ni su infancia

\footnotetext{
${ }^{12}$ Ojito cita un artículo de fondo publicado el 27 de abril en el periódico cubano Granma (2006, p. 194).

${ }^{13}$ Véase la observación que aparece en Todos se van: "A veces hasta arrastran por el suelo a los que se van. [...] Están igual que mi padre, golpes y golpes sin dejar que uno pueda ir a donde quiera" (GUERRA, 2006, p. 123-124).
} 
ni su patria le pertenecen ya, de modo que la memoria diaspórica se constituye como una memoria sin refugio:

La patria, ese concepto elusivo para los refugiados dondequiera que estén, dondequiera que vayan, continúa evadiéndome, como un espejismo en el desierto, que se aleja mientras más cerca creo estar. Cuando volví a Cuba en 1998, me sentía en casa al caminar las calles de mi infancia, entre la gente con que me crié, pero extrañamente fuera de lugar en otras partes. Me sentía incompleta, asediada por una sensación familiar de desasosiego, de no estar realmente en ninguna parte, como flotando. El exilio, supe entonces, no es un estado temporal que se disipa en la euforia del regreso. El exilio, como la añoranza, es un modo de vida [...] (OJITO, 2006, p. 318).

\section{Conclusión}

En ambas novelas se destaca que el miedo a la separación constituye el tema central de la reconstrucción narrativa de la infancia. Sin embargo, se observa una diferencia fundamental en la comparación de ambas protagonistas de las novelas que corresponde a las biografías empíricas de las escritoras: una permanece en la isla pero queda separada de los demás, otra se va y se separa de su tierra natal. Esta diferencia influye en la dimensión memorística de los textos: Mirta sufre del anhelo por su tierra perdida, Nieve soporta el abandono en una isla que se ha vuelto prisión. A pesar de las diferentes perspectivas, las escritoras muestran cómo las partidas y las pérdidas predominan en el mundo de la infancia y cómo impactan en la diasporización de la sociedad cubana dentro del marco íntimo de las familias que se desmiembran. Nos hacen ver, además, que dentro del país socialista, que se autorrepresenta como un bloque de absoluta unanimidad, la cohesión social está profundamente fracturada.

Ambos textos autobiográficos no reconstruyen una Cuba como lugar idílico, sino como espacio inhabitable. Recuperando los conflictos vividos, las escritoras retan el discurso oficial homogeneizador del castrismo con unas memorias en las que resuena(n) toda(s) la(s) historia(s) oficialmente silenciada(s) en la isla. Sin embargo, estas memorias se han descentralizado y transnacionalizado, tomando en cuenta que Wendy Guerra publica sus libros en España y Mirta Ojito lo hace en los Estados Unidos, además de 
publicarlo en inglés. Los recuerdos que recapitulan el proceso de la diáspora cubana crean una memoria diaspórica que no logra encontrar un refugio en los recuerdos, sino que revisita la infancia como lugar desubicado y tiempo desconcertante, como símbolo de una nación profundamente dividida y desgarrada. La transnacionalización de la literatura cubana se escribe desde las infancias perdidas y desde sus huellas de abandono irrecuperable. Como apelaciones a una memoria colectiva, los textos de Wendy Guerra y Mirta Ojito nos recuerdan que las experiencias de estas pérdidas y separaciones finalmente reúnen a todos los cubanos dentro y fuera de la isla.

\section{Bibliografía}

ANDERSON, Benedict. Imagined Communities. Reflections on the origin and spread of nationalism. London: Verso, 1983.

ASSMANN, Jan / CZAPLICKA, John. Collective Memory and Cultural Identity. New German Critique v. 65, Cultural History / Cultural Studies, p. 125-133, 1995.

BRIAND, Sylvie. Escritores cubanos descartan exilio y narran dura realidad. El Nuevo Herald del 14 mayo 2009.

Disponible en: «http://www.elnuevoherald.com/2009/05/13/449367/escritores-cubanosdescartan-exilio.html.. Acceso el: 28 mar. 2015.

COLPRENSA. Todos se van, el regreso cinematográfico de Sergio Cabrera. El Colombiano del 3 mar. 2015. Disponible en: ‘http://www.elcolombiano.com/todos-se-van-el-regresocinematografico-de-sergio-cabrera-DX1415775'. Acceso el: 28 mar. 2015.

CORRESPONDAL-NOTICINE.COM. Sergio Cabrera vuelve a la gran pantalla con "Todos se van". Disponible en: «http://www.noticine.com/iberoamerica/36-iberoamerica/19751sergio-cabrera-vuelve-a-la-gran-pantalla-con-qtodos-se-vanq.html. Acceso el: 28 mar. 2015.

ERLL, Astrid. Literatur als Medium kollektiven Gedächtnisses. En: ERLL, Astrid / NÜNNING, Ansgar (Org.): Gedächtniskonzepte der Literaturwissenschaft. Theoretische Grundlegung und Anwendungsperspektiven. Berlin / New York: de Gruyter, 2005, p. 249-276.

ERLL, Astrid. Travelling Memory. Parallax, v. 17, n. 4, 2011, p. 4-18.

FERNÁNDEZ-HALL, Lilian. Testimonio y poesía en "Todos se van" de Wendy Guerra, 2007. 
Disponible en: 〈http://www.letras.s5.com/lf110707.htm〉. Acceso el: 28 mar. 2015.

GUERRA, Wendy. Todos se van. Barcelona: Bruguera, 2006.

HALBWACHS, Maurice. La Mémoire collective. ALEXANDRE, Jeanne (org.). Paris: Presses Universitaires de France, 1950.

LEJEUNE, Philippe. Le Pacte Autobiographique. Paris: Seuil, 1975.

MAYER, Ruth. Diaspora. Eine kritische Begriffsbestimmung. Bielefeld: transcript, 2005.

MICHEL, Charlotte. El juego de los géneros en Wendy Guerra - Narrativa, 2011.

Disponible en: «http://cle.ens-lyon.fr/espagnol/el-juego-de-los-generos-en-wendy-guerranarrativa-114076.kjsp». Acceso el: 28 mar. 2015.

NUEZ, Iván de la. La balsa perpetua. Barcelona: Editorial Casiopea, 1998.

OJITO, Mirta. El Mañana: memorias de un éxodo cubano. New York: Random House/Vintage Español, 2006.

SAFRAN, William. Diasporas in Modern Societies. Myths of Homeland and Return. In: Diaspora, v. 1, n. 1, p. 83-89, 1991.

WHITFIELD, Esther. Cuban currency. The dollar and 'special period' fiction. Minneapolis: University of Minnesota Press, 2008.

ZIPFEL, Frank. Autofiktion. Zwischen den Grenzen von Faktualität, Fiktionalität und Literarität?. En: JANNIDIS, Fortis / LAUER, Gerhard / WINKO, Simone (Org.). Grenzen der Literatur. Zu Begriff und Phänomen des Literarischen. Berlin: de Gruyter, 2009, p. 283314. 
Recebido em 28/02/2015 Aprovado em 19/03/2015

Universidade do Estado de Santa Catarina - UDESC Programa de Pós-Graduação em História - PPGH Revista Tempo e Argumento Volume 07 - Número 14 - Ano 2015 tempoeargumento@gmail.com 